\title{
Focussed Ion Beam Scanning Electron Microscopy in Biology
}

\author{
Caroline Kizilyaprak, Céline Loussert, Jean Daraspe, and Bruno M. Humbel
}

Electron Microscopy Facility, University of Lausanne, Lausanne, Switzerland

There is a long way since the first focussed ion beam instrument was described in 1974 by Seliger and Fleming $[1,2]$ to the present day applications. For many years focussed ion beam applications were only in the domain of semiconductor industry. One of the first applications in biology was making cross-sections to image the eye of a housefly [3]. This application was further extended by biologists [4] to analyze internal structures of Porcellio scaber. Later the focussed ion beam was used to analyze difficult to cut material such as bone and dental implant $[5,6]$.

In the last 20 years electron microscopy has more actively made the step from two-dimensional images to the third dimension like light microscopy did in the eighties. The main reason for this progress was the increased computer power and the computerization of the electron microscopes. Transmission electron tomography (TEM tomography) [7-9] provides valuable information on the organization of intracellular organelles [e.g., 10] or the structure of proteins in situ [11]. This technology, however, is limited to a small field of view, in the range of micrometers in $\mathrm{X}$ and $\mathrm{Y}$ and $500 \mathrm{~nm}$ in $\mathrm{Z}$, but usually at a high resolution in the range of $1-2 \mathrm{~nm}$.

For cell biology, where cell-cell interactions become important and whole organelles, such as a Golgi apparatus, need to be examined, TEM tomography can become rather tedious [12] and other approaches need to be sought. In the field of neurobiology [e.g., 13] serial sectioning was used to study the complex arrangement of neurons and the interaction through synapses. Serial sectioning is very time consuming and needs a lot of skills and patience of the investigator. In addition the sections can easily be lost by destroying the delicate support film of the electron microscopy grid. More automated approaches would be more than welcome. In 2004 Denk and Horstmann [14] introduced an ultramicrotome integrated into a scanning electron microscope. The microtome cuts off a section from a resin embedded brain sample and the new surface is imaged in the SEM, usually using backs-scattered electrons. Then again a section is removed from the block and the new surface is imaged with the electron beam. This process can be repeated to analyse large organism, such as a whole planarian [15]. With this method large volumes up to millimetres can be analysed of course on the costs of resolution.

With the fossused ion beam scanning electron microscope (FIB-SEM) and intermediate instrument became available for tomography $[16,17]$. Instead of using a real knife as with the 3 View, sections are removed with the focussed ion beam, imaging is done the same way. The volume to be analyzed can be in the range of $50 \times 50 \times 50$ micron, with a voxel resolution of about $5 \mathrm{~nm}$. FIB-SEM tomography has shown to be effective in different areas of biology [18-22], again neurobiology seems to be the main target for this application [23].

The limit of the resolution but also the processing time is dependent on the intensity of the signal that again is dependent on the electron current used for imaging. Resins on the other side are quite sensitive to beam irradiation resulting in deformation, mass loss and shrinkage [for review see 24]. To optimize the sample preparation method for tomography we analyzed a set of resin formulations for their stability in the electron beam. Unfortunately but not surprisingly all resins are affected but not all to the same extend. The results obtained will be discussed during the presentation. 
The most interesting possibilities of the FIB-SEM instrument is its potential to analyze a very precise region of interest. This region of interest is defined by a fluorescence label and with what is called correlative light -electron microscopy the labelled cell is 'marked' and retrieved in the electron microscope. Here we will show our approach of correlative light - FIB-SEM. We base our work on hepatocytes transfected with a modified virus, expressing GFP and a gene of interest. In this case cells expressing the modified gene can be specifically localised with their GFP expression and further analyzed by FIB-SEM tomography.

\section{References:}

[1] Seliger, R.L. and W.P. Fleming, Journal of Applied Physics 45 (1974). p. 1416-1422.

[2] Sugiyama, M. and G. Sigesato, Journal of Electron Microscopy 53 (2004). p. 527-536.

[3] Ishitani, T., H. Hirose, and H. Tsuboi, Journal of Electron Microscopy 44 (1995). p. 110-114.

[4] Drobne, D., et al., Journal of Microscopy 219 (2005). p. 29-35.

[5] Giannuzzi, L.A., et al., Journal of Oral and Maxillofacial Surgery 65 (2007). p. 737-747.

[6] Nalla, R.K., et al., Micron 36 (2005). p. 672-680.

[7] Crowther, R.A., D.J. DeRosier, and A. Klug, Proceedings of the Royal Society of London. Series A, Mathematical Physical and Engineering Sciences 317 (1970). p. 319.

[8] Hoppe, W. and B. Grill, Ultramicroscopy 2 (1977). p. 153-168.

[9] Koster, A.J., et al., Journal of Structural Biology 120 (1997). p. 276-308.

[10] Marsh, B.J., et al., Proceedings of the National Academy of Science USA 101 (2004). p. 55655570 .

[11] Al-Amoudi, A., et al., Nature 450 (2007). p. 832-837.

[12] Marsh, B.J., Methods in Cell Biology 79 (2007). p. 193-220.

[13] Young, H.M. and J.B. Furness, J. Comp. Neurol. 356 (1995). p. 101-14.

[14] Denk, W. and H. Horstmann, PLoS Biology 2 (2004). p. 1900-1909.

[15] Pellettieri, J., et al., Developmental Biology 338 (2010). p. 76-85.

[16] Inkson, B.J., M. Mulvihill, and G. Möbus, Scripta Materialia 45 (2001). p. 753-758.

[17] Holzer, L., et al., Journal of Microscopy 216 (2004). p. 84-95.

[18] Heymann, J.A.W., et al., Journal of Structural Biology 155 (2006). p. 63-73.

[19] De Winter, D.A.M., et al., Journal of Microscopy 233 (2009). p. 372-383.

[20] Heymann, J.A.W., et al., Journal of Structural Biology 166 (2009). p. 1-7.

[21] Schroeder-Reiter, E., et al., Journal of Structural Biology 165 (2009). p. 97-106.

[22] Lamers, E., et al., Tissue Engineering Part C: Methods 17 (2011). p. 1-7.

[23] Knott, G., et al., Journal of Neuroscience 28 (2008). p. 2959 -2964.

[24] Luther, P.K., in "Electron Tomography. Three-dimensional imaging with the transmission electron microscope", J. Frank ed., (Springer: New York) (2007) p. 17-48.

[25] The authors acknowledge the financial support by the Faculty of Biology and Medicine of the University of Lausanne and by the R'Equip grant 316030_128692 of the Swiss National Science Foundation and the Dr. K. Minehira for providing samples. 